\title{
Quick and easy: 1-day-protocol for detection of normal alternative splicing events and aberrant spliceogenic transcripts with deep RNA sequencing
}

Vita Šetrajčič Dragošn ${ }^{1}$, Vida Stegel ${ }^{1}$, Ana Blatnik ${ }^{2}$, Gašper Klančar ${ }^{1}$, Mateja Krajc ${ }^{2}$, and Srdjan Novaković ${ }^{2}$

${ }^{1}$ Institute of Oncology Ljubljana

${ }^{2}$ Onkoloski Institut Ljubljana

March 14, 2021

\begin{abstract}
RNA sequencing is a promising technique for detecting normal and aberrant RNA isoforms. Here, we present a new singlegene, straightforward 1-day hands-on protocol for detection of splicing alterations with deep RNA sequencing from blood. We have validated our method's accuracy by detecting all normal splicing isoforms of STK11 gene that were previously published. Additionally, the same technique was used to provide the first comprehensive catalogue of naturally occurring alternative splicing events of the NBN gene in blood. Furthermore, we demonstrate that our approach can be used for detection of splicing impairment caused by genetics variants. Due to the simplicity of our approach it can be incorporated into any molecular diagnostics laboratory for determination of variant's impact on splicing.
\end{abstract}

\section{Hosted file}

Quick and easy RNAseq _2021-HumanMutation.pdf available at https://authorea.com/users/401506/ articles/513576-quick-and-easy-1-day-protocol-for-detection-of-normal-alternativesplicing-events-and-aberrant-spliceogenic-transcripts-with-deep-rna-sequencing

\section{Hosted file}

Quick and easy RNAseq_2021-Tables1-2.pdf available at https://authorea.com/users/401506/ articles/513576-quick-and-easy-1-day-protocol-for-detection-of-normal-alternativesplicing-events-and-aberrant-spliceogenic-transcripts-with-deep-rna-sequencing 

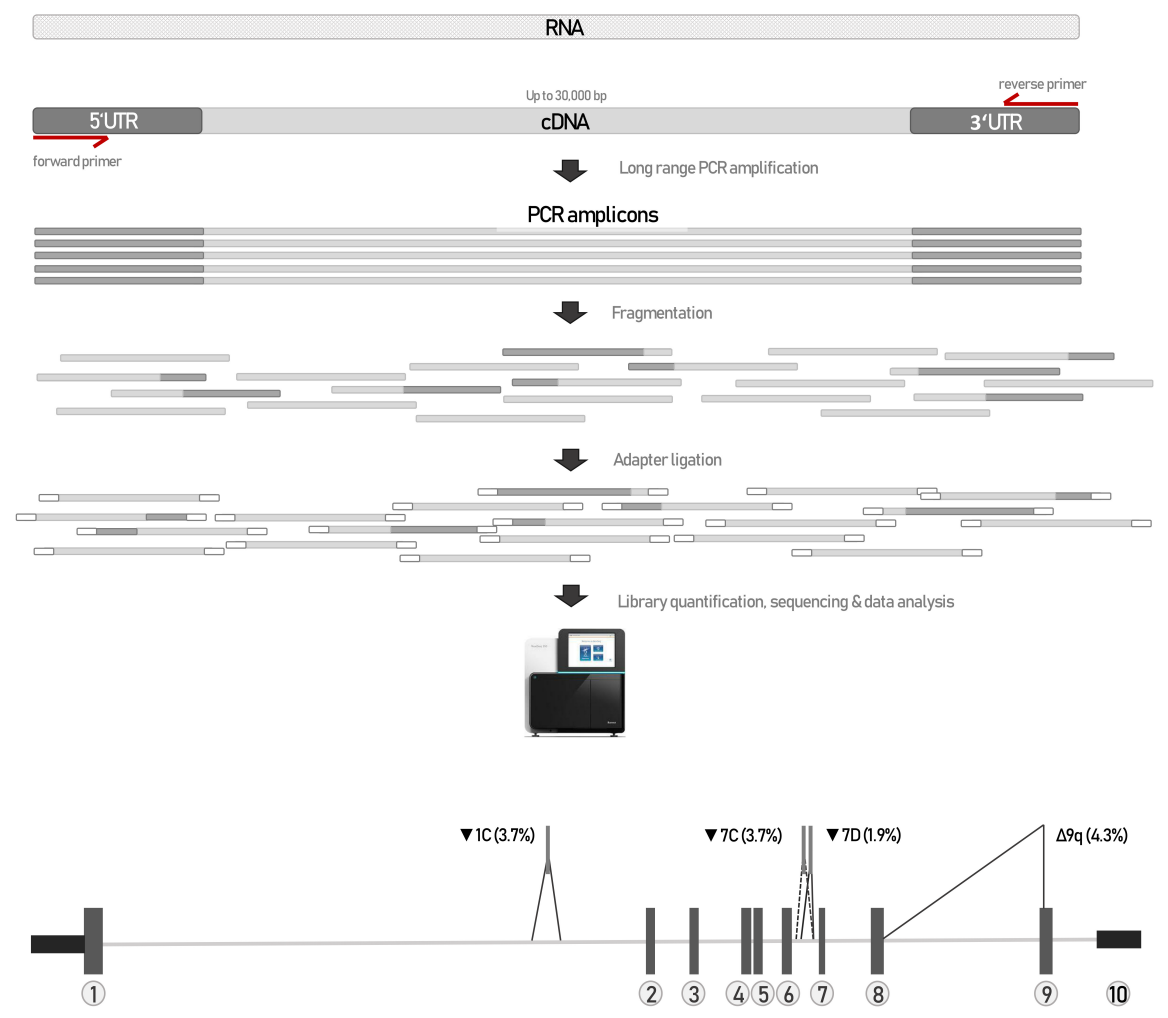

STK11 (NM_000455.4)

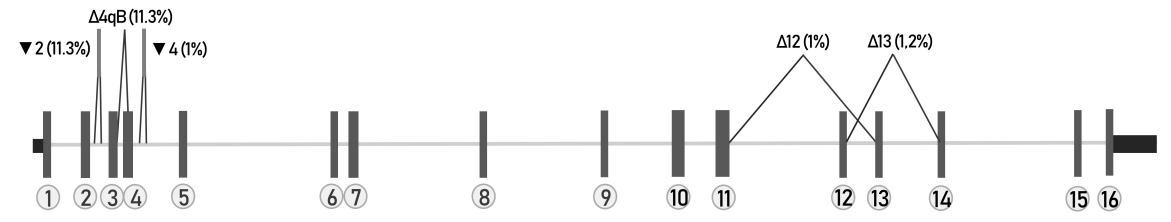
NBN (NM_002485.4) 


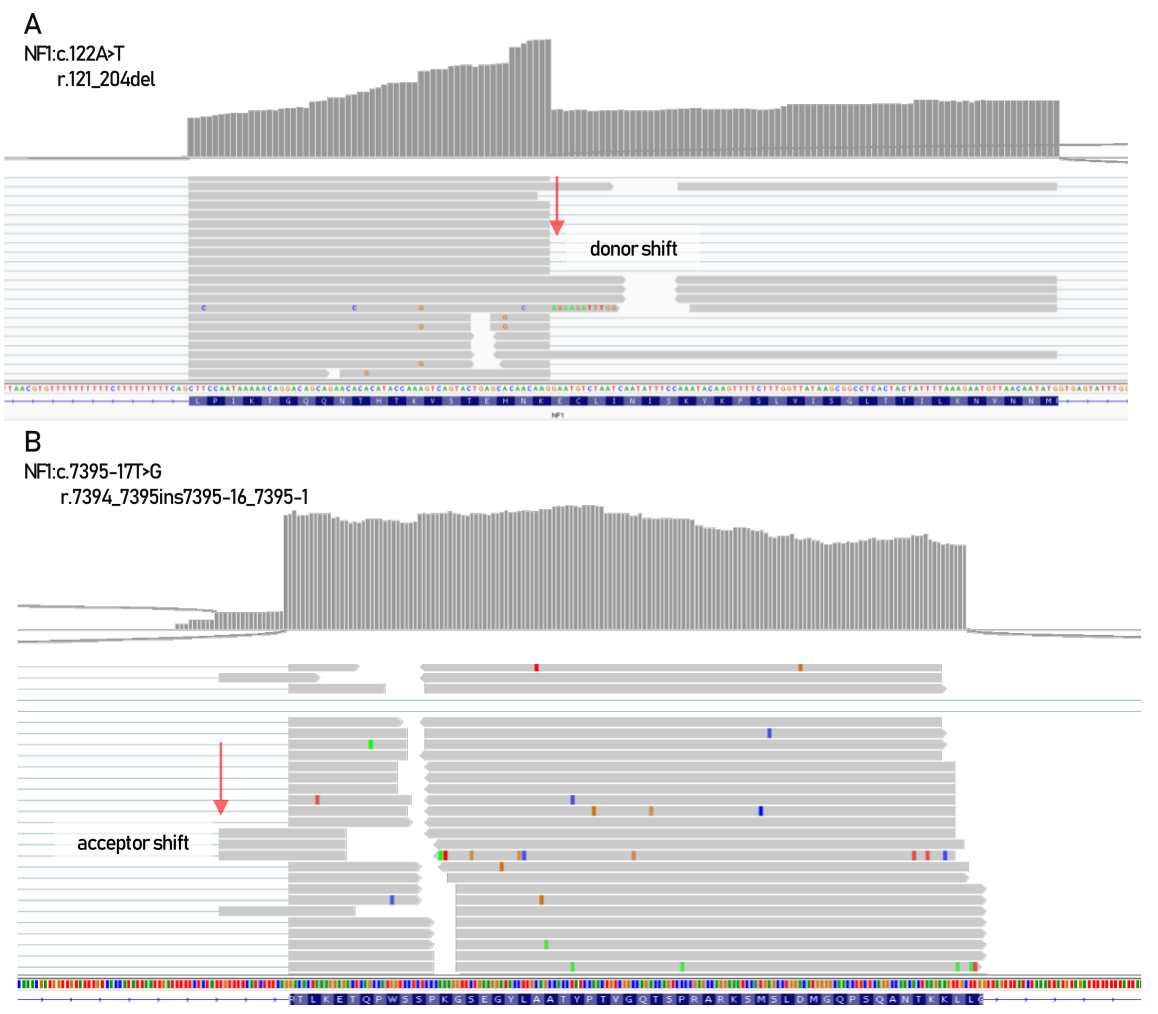

